\title{
SKELETAL PATTERN CLASSIFICATION IN DOWN'S SYNDROME PATIENTS: CLINICAL AND RADIOGRAPHIC STUDY
}

\author{
Hazem M. Marzouk* and Wafa M. Al-Faleh**
}

\begin{abstract}
Down's syndrome (DS) is a genetic disorder that results from a chromosomal abnormality due to trisomy of chromosome 21. Any disturbances during the early formation of the maxillofacial structures may lead to skeletal abnormalities. DS patients have been reported to experience malocclusions to a greater degree.
\end{abstract}

Objective of this study is to investigate the skeletal abnormalities among DS patients.

Subjects and Methods: The clinical examination and Cephalometric analysis were carried out for $30 \mathrm{DS}$ patients and 30 control subjects. The prevalence of skeletal patterns were determined and compared to the findings of healthy controls.

Results: Based on Cephalometric analysis, the most common skeletal arch relationship in DS was the Class III skeletal arch relationship as it was found in $16(53.3 \%)$ with vertical growth pattern tendency and a more obtuse mandibular angle. Clinically the most common occlusal arch relationship was the class III, which was found in $70 \%$ of the patients. Descriptive characteristics such as cross bites, open bites were frequently observed in the DS group. Anterior open bite, anterior cross bite and posterior cross bites were found in $46.7 \%, 30 \%$ and $53.3 \%$ of the DS patients respectively.

Conclusion: A significant difference is clear between DS subjects and controls when examining cephalometric radiographs regarding skeletal patterns as well as other clinical descriptive occlusal characteristics.

KEY WORDS: Down's syndrome, skeletal pattern, Cephalometric analysis.

\section{INTRODUCTION}

The development of occlusion is a complex process that is determined genetically; and may be influenced by other environmental or systemic factors. The craniofacial skeletal growth has an important role in the development of occlusion, since variations in craniofacial morphology are the source of most serious malocclusions. Any disturbances or insults during the early formation

* Lecturer, Dept. of Oral \& Maxillofacial Radiology, Faculty of Oral and Dental Medicine, Cairo Univ., Egypt Assistant Professor, Dept. of Oral Medicine and Diagnostic Sciences, College of Dentistry, King Saud Univ., KSA ** BDS, MSc, Associate professor, College of Dentistry, King Saud University, Saudi Arabia. 
of the maxillofacial structures may lead to skeletal jaws relationship abnormalities. ${ }^{1}$

DS was first described in 1866 by John Langdon Down and affects 1 in every 600-1000 live Births ${ }^{2}$. Patients with DS have been reported to experience malocclusion and mal-alignments of teeth to a greater degree. ${ }^{3,4}$

The majority of malocclusions result from either a relative discrepancy between the sizes of teeth and the sizes of the jaws available to accommodate those teeth or disharmonies of facial skeletal patterns. Both of these general conditions are innate to the patient and are essentially genetically determined. ${ }^{1,2}$

Normal occlusion is considered when irregularities, if present, do not adversely affect the function, health and esthetics. However, any deviation in the arrangement of the teeth exceeding the standards of normal occlusion is called malocclusion. The primary etiologic sites of malocclusion are the craniofacial skeleton, the dentitions, the orofacial musculature and other soft tissues of the masticatory system. ${ }^{5}$

Maxillofacial abnormalities in DS have been frequently described in the literature. These include hypomaxilla, anterior open bites, anterior and posterior cross bites, crowded teeth, widely spaced teeth and a high prevalence of class III malocclusion. ${ }^{3,6,7,8}$

Many of studies conducted for DS skeletal abnormalities reported that class III skeletal pattern is the main expressed pattern $9,10,11,12$

Although the mandibular angular deviation from normal values have been debated among the previous studies ${ }^{10,12,13,14}$, the same was applied regarding the angle between the Frankfort plane and the mandibular plane to determine the maxillofacial growth pattern.

Therefore the aim of this study was to investigate the skeletal abnormalities among DS patients in comparison to normal subjects.

\section{SUBJECTS AND METHODS}

Thirty DS patients of both genders at an age range from 12 to 24 years were included in this study. Different hospitals, DS care centers and schools in Riyadh, KSA were contacted. Contact lists of all individuals affected with DS in the age range of interest were obtained. Families were contacted and the study was explained to them. All DS patients are proven to be affected by the genetic abnormality based on a chromosomal analysis by a Karyotype test (Group I). This was found in the medical files or school files of each individual.

The control group (Group II) included thirty normal subjects of both genders with matching age ranges. The controls were selected by explaining the study to the mothers in the King Khalid University Hospital waiting area. Those who agreed in to participate in the study were contacted and included as controls, in order to compare the rate of prevalence of occlusion disharmonies between the two groups.

All patients were seen at the dental clinics of the College of Dentistry, King Saud University. All the patients were subjected to a detailed case history, thorough clinical and Cephalometric radiographic examinations unless recent radiographs were available. Also, information regarding age, gender, medical history and history of dental extractions was recorded. Intraoral clinical examination was performed for tooth abnormalities and disharmonies of occlusion following specific parameters. Abnormalities were recorded in a specially prepared examination form.

Consents were obtained from patient's guardian for each case prior to the examination procedures.

Discrepancies of Occlusion clinically: Anterior Open Bite: Established when there is no vertical overlap of the incisors when the buccal segment teeth are in occlusion. Anterior Cross Bite: Established when one or more of the upper incisors is in linguoocclusion (i.e. in reverse overjet) relative to the lower arch. Posterior Cross Bite: Established when the buccal cusps of the lower teeth occlude buccal to the buccal cusps of the upper teeth. Alignment 
problems: Spacing: Established when increase distance exists between adjacent teeth in the anterior segment of teeth. Crowding: Established when decreased distance exists between adjacent anterior teeth leading to overlapping of teeth or ectopic eruption. Occlusal arch relation: classified according to the Angle classification.

Radiographic Examination: Lateral cephalometric radiograph were performed for both groups, the radiographs were done at the College of Dentistry, King Saud University. Radiographs were taken using the Planmeca Proline EC machine, with a tube voltage of $57-85 \mathrm{Kv}$ and a tube current of 2-16 mA using cranex intensifying screen (HI plus regular speed) under strict radiation protection measures.

The cephalometric radiographs were digitized using M Pro Scanner, (Epson perfection V750-M ProScanner, Seiko Epson Corp, Tokyo, Japan) and traced by expert orthodontist. Skeletal arch relationship was determined radiographically by performing cephalometric sagittal analysis; also the gonial angle of the mandible is recorded using orthodontic imaging and management solutions software (Onyx, OnyxCeph ${ }^{\mathrm{TM}}$ 2D Pro-OSL, MC LAUGHLIN analysis). Descriptive analysis for continuous variables was reported as mean values, range and standard deviation. Categorical variables were summarized as frequencies and percentages. The comparisons between DS patients and control group were performed using Person's chi-square test with statistical significance set at $\mathrm{P}<0.05$. Statistical package of the Social Sciences (SPSS) was used for all the statistical analysis.

\section{RESULTS}

The study sample consisted of two groups. There were 30 patients in both groups. In each group there were 14 males and 16 females with an age range from 12 to 24 years. In the DS group, the mean age was 15.93 years SD (3.3), whereas, in the control group the mean age was $14.73 \mathrm{SD}$ (3) years.
Based on Angles classification for occlusal arch relationships, $70 \%$ of the DS subjects had Class III malocclusion clinically. To a lesser degree class II and I malocclusion were found as they were recorded in only $16.7 \%$ and $13.3 \%$ respectively.

In the control group, the most common occlusal relationship is Class I, as it was found in the majority of the patients in this group 16 (53.3\%), where as Class II and Class III malocclusions were detected with the same frequency 7 (23.3\%) of the cases.

Based on Cephalometric analysis for skeletal arch relationship, the radiographic analysis emphasized that Class III malocclusion was the most common findings in group I as it was recorded in $53.3 \%$ (Fig. 1). This skeletal relationship was caused by prognathism of the mandible in $60 \%$ of the cases, whereas, the remaining $40 \%$ were due to a hypoplastic maxilla. However, Class I and Class II were recorded less frequently (table 1).

Regarding the gonial angle of the mandible, there was highly statistically significant difference between the DS patients and the control group, whereas the measurements of the DS group were larger than the control group (table 2).

Regarding the growth pattern, the angle between the Frankfort plane (orbital rim lower most point to porion) and the mandibular plane (menton to gonion), a significant difference between DS group and the control group was found (vertical growth pattern tendency in DS group). (table 2).

Based on the clinical examination, the anterior open bite was a very common finding as it was found in 14 (46.7\%) of the DS patients (Figure 2 A). Anterior cross bite was not a common finding as it was recorded in $9(30 \%)$ cases, however, posterior cross bite recorded in 16 cases (53.3\%) (Figure $2 \mathrm{~B}$ ). Crowding was observed in 13 (43.3\%) and spacing in $14(46.7 \%)$ of the patients. 
In the control group, anterior open bite was not commonly recorded as it was found in 2 cases $(6.7 \%)$. In addition, anterior and posterior cross bites were found in $1(3.3 \%)$ of the patients. Crowding was found in 13 cases (43.3\%) and was found more in the lower anterior segment. Spacing was found in
$3(10 \%)$ cases, more in the upper anterior segment.

Using the Person's chi-square test, there was a significance difference between group I and group II regarding anterior open bite, anterior cross bite, posterior cross bite, occlusal arch relationships and spacing of the anterior teeth (table 3 ).

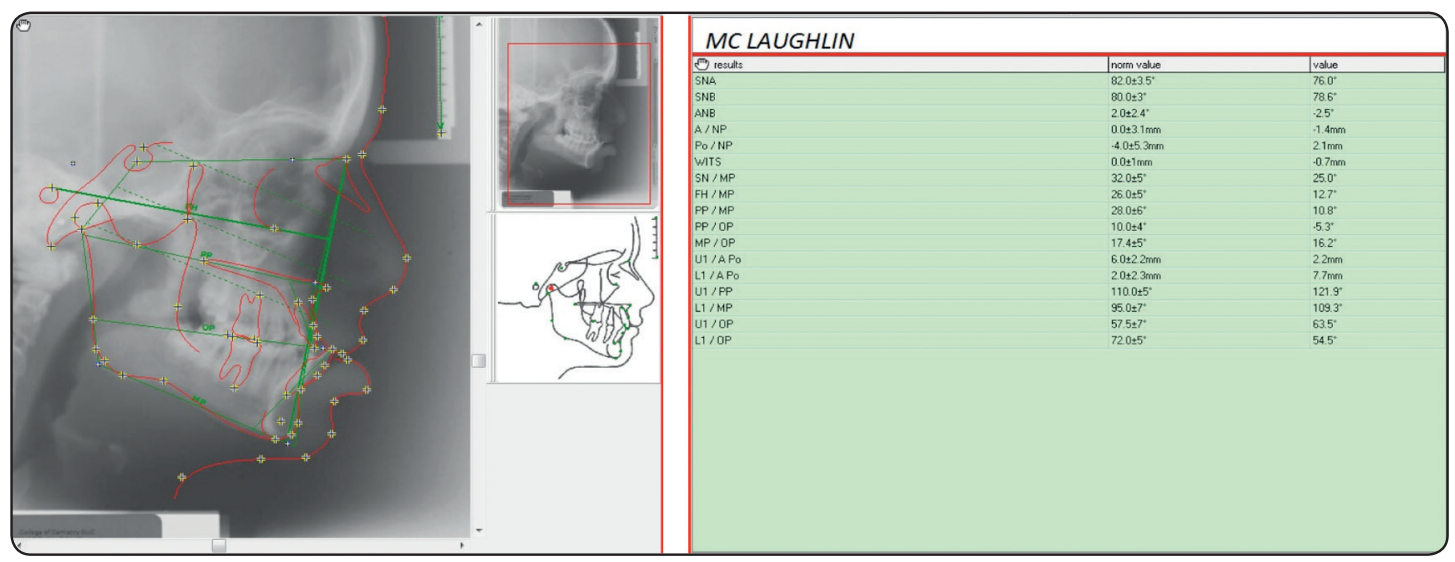

Fig. (1) Lateral cephalometric analysis of DS case shows class III skeletal pattern (ANB $\left.-2.5^{\circ}\right)$, maxillary deficiency $\left(\mathrm{SNA} 76^{\circ}\right)$.

TABLE (1) The frequency and percentages of cephalometric skeletal arch relationship in both groups.

\begin{tabular}{|c|c|c|c|c|c|c|c|}
\hline & \multicolumn{4}{|c|}{ DS group } & \multirow[b]{2}{*}{$\begin{array}{l}\text { Control group } \\
\text { Frequency }(\%)\end{array}$} & \multirow[b]{2}{*}{$\begin{array}{c}\text { *P value } \\
\text { For both } \\
\text { groups }\end{array}$} \\
\hline & & $\begin{array}{l}\text { Males } \\
\text { Frequency (\%) } \\
\text { within gender }\end{array}$ & $\begin{array}{l}\text { Females } \\
\text { Frequency }(\%) \\
\text { within gender }\end{array}$ & $P$ value & $\begin{array}{l}\text { Total } \\
\text { Frequency } \\
(\%)\end{array}$ & & \\
\hline \multirow{3}{*}{$\begin{array}{l}\text { Skeletal arch } \\
\text { relationship }\end{array}$} & Class I & $1(7.7)$ & $4(23.5)$ & \multirow{3}{*}{0.43} & $5(16.7)$ & $8(26.7)$ & \multirow{3}{*}{0.01} \\
\hline & Class II & $5(38.5)$ & $4(23.5)$ & & $9(30)$ & $17(56.7)$ & \\
\hline & Class III & 7 (53.8) & $9(53)$ & & $16(53.3)$ & 5 (16.7) & \\
\hline
\end{tabular}

TABLE (2) The measurements of the angle of the mandible and the angle between the Frankfort plane and the mandibular plane in both groups

\begin{tabular}{|c|c|c|c|}
\hline & DS group & Control group & P value \\
\hline Angle of the mandible & $132.4(\mathrm{st} \pm 5.2)$ & $124.8(\mathrm{st} \pm 4.1)$ & $<.0001$ \\
\hline Growth pattern angle & $34.4(\mathrm{st} \pm 2.8)$ & $27.8(\mathrm{st} \pm 3.2)$ & $<.001$ \\
\hline
\end{tabular}


TABLE (3) The frequencies, percentages and P value of the Chi-square test of the disharmonies of occlusion among both groups.

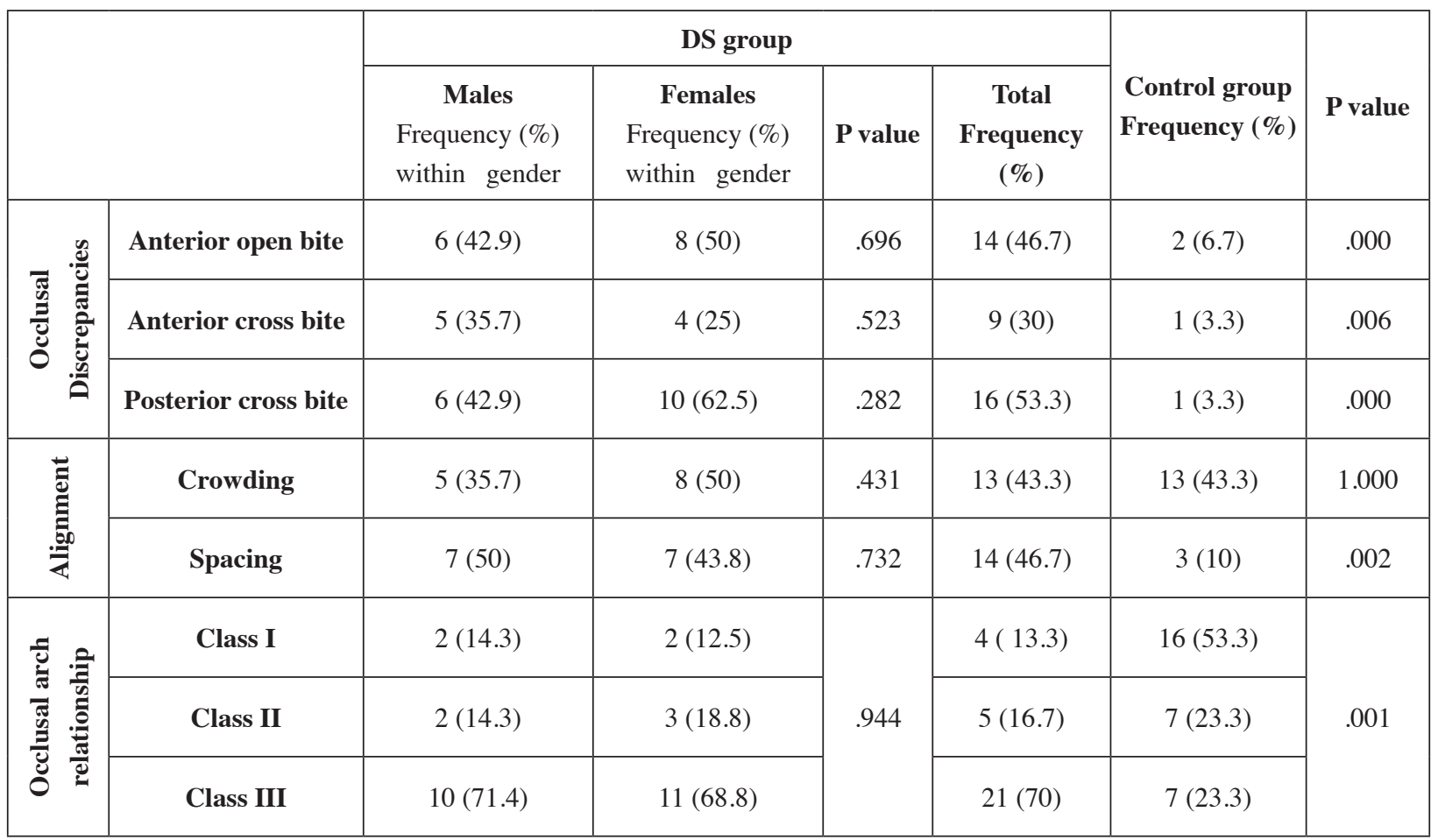

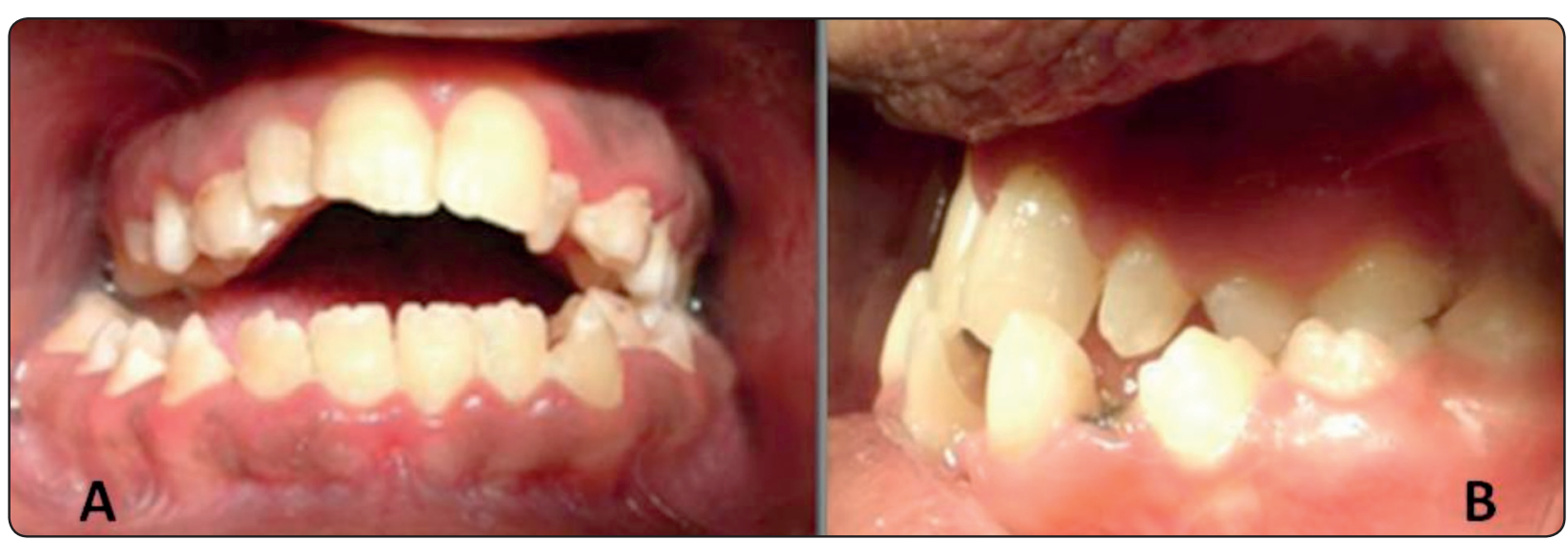

Fig. (2) A- Anterior open bite, B- posterior cross bite in DS group.

\section{DISCUSSION}

In this study, patients of age range 12-24 years were included. This age range represents the late mixed to the permanent dentition in which the occlusion may be more stable to evaluate. This is believed to be more accurate than those studies which have included very young patients ${ }^{15,16}$ which justifies performing the present study.
In this study, class III malocclusion was the most common type of occlusal arch relationship encountered in the DS group. This finding is in agreement with the results obtained by most of studies on DS $16,17,18,19$

However, this finding disagrees to the finding reported by Cohen, et al. ${ }^{19}$ and Oredugba ${ }^{20,21}$ who found class I more common. 
In the present study, Cephalometric analysis was performed to determine the extent of hypoplastic maxilla and to determine if the skeletal class III is due to a hypoplastic maxilla as proposed in the literature or due to a true prognathism of the mandible. This may provide a more objective approach than those studies that evaluated this feature subjectively from skull radiographs (Spitzer \& Quilliam, 1958; Spitzer et al., 1961; Spitzer, 1967; Jensen et al., 1973). ${ }^{22-25}$

The Cephalometric analysis revealed that 60 $\%$ of DS group subjects represent class III skeletal arch relationship with true mandibular prognathism, however in $40 \%$ it was caused by a hypoplastic maxilla. Therefore the results of the present study are different from Korayem and Alkofide ${ }^{13}$, who have considered that the class III in DS patients is related to a hypoplastic maxilla and their mandibular measurements did not show any significant difference from normal.

Also these results did not match the findings of Frostad et al. ${ }^{9}$ who concluded that the overall size of the young DS craniofacial complex was smaller, with the maxilla being more retrognathic. This could be attributed to that these studies were conducted on a younger age group where the maxilla and the mandible were in the growth stage while this study older age group permitted well development of the maxilla and the mandible.

On the other hand, the current study findings come in equivalent to Quintanilla et al ${ }^{14}$ who found that the craniofacial parameters for maxillary depths indicated average values within the clinical normal values.

Regarding the angle of the mandible, the current study revealed a highly statistic difference between the two groups, this finding comes congruent to Korayem and Alkofide ${ }^{13}$.

For the growth pattern our study revealed a vertical growth pattern tendency with a significant difference of the DS group patients. Which matches Korayem and Alkofide ${ }^{13}$ findings regarding this point, but in contrary to the results shown by
Quintanilla et al. ${ }^{14}$ who revealed in their analysis that DS subjects have a tendency toward a normal mandibular growth pattern rather than vertical; however, their study did not compare DS subjects to matching controls. In addition, this difference could be related to population dissimilarity.

Anterior open bite was found in the DS patients in our study sample. This finding in acceptance with those reported by many studies 26,27,28,29 despite of the different age groups of their samples. However, Oliveira, et al. ${ }^{15}$ reported that anterior open bite was found in only $21 \%$ of their study sample. Cohen \& Winer ${ }^{18}$ did not report any cases of anterior open bite among the patients with an age range from 1330 years.

The results of the previous studies reported anterior cross bite in the range of $15.5 \%-50 \%{ }^{15,25,26}$. The results of this study fall within this range which was observed in $30 \%$ of the DS group. However, because patients with anterior open bites or cross bites cannot attain contact between the incisors anteriorally, this may contribute to the production of a lisp affecting the speech. In addition, this may lead to difficulty with eating, particularly when incising food ${ }^{30}$. The result obtained for posterior cross bites is in acceptance with that reported by others ${ }^{15,17,25,26}$.

In this study, the results of crowding of the teeth were in acceptance with the findings described by Asokan, et al. ${ }^{26}$ and Oredugba ${ }^{21}$. However, it was higher than the findings of Brown \& Cunningham ${ }^{17}$. Crowding observed in this study could be attributed to disproportionately sized teeth and jaws.

Conclusion: proper investigation of the skeletal pattern and disharmonies of DS patients is mandatory via precise radiographic and clinical analysis for early intervention as well as follow up for the cases and the growth progress tracking.

Delving into a larger sample size may give a more precise judgment regarding the nature and cause of developing class III skeletal arch relationship among DS patients. 


\section{ACKNOWLEDGMENTS}

The authors would like to express deep appreciation for Dr. Tamer Amer, orthodontist at educational dental hospital of Cairo university - Faculty of oral and dental medicine for his meaningful help in preparing and analyzing this article.

\section{REFERENCES}

1 - Moyers R. Hand book of orthodontics. 3rd ed. Chicago: Year Book, 1973.

2 - M. B. Petersen and M.Mikkelsen, "Nondisjunction in trisomy 21: origin and mechanisms," Cytogenetics and Cell Genetics, vol. 91, no. 1-4, pp. 199-203, 2000.

3 - Desai SS. Down syndrome: a review of the literature. Oral Surg Oral Med Oral Pathol Oral Radiol Endod 1997;84(3):279-85.

4 - Horbelt CV. Down syndrome: a review of common physical and oral characteristics. Gen Dent 2007;55(5):399-402.

5 - Thilander B, Rönning O. Introduction to orthodontics 2nd ed. Sweden: Gothia, 1995.

6 - Regezi JA, Sciubba JJ. Oral pathology: clinical pathologic correlations. 3rd ed. Philadelphia: Saunders, 1999.

7 - Gorlin RJ, Cohen MM, Hennekam RCM. Syndromes of the Head and Neck 4th ed. New York: Oxford University Press, 2001.

8 - E. S. Pilcher, "Dental care for the patient with Down Syndrome" Down Syndrome Research and Practice, vol. 5, no. 3, pp. 111-116, 1998.

9 - Frostad W, Cleall J, Melosky L. The craniofacial complex in the trisomy 21 syndrome (Down's syndrome). Arch Oral Biol. 1971;16:707-722

10 - Fink G, Madaus W, Walker G. A quantitative study of the face in Down's syndrome. Am J Orthod Dentofacial Orthop.1975;67:540-553

11 - Fischer-Brandies H. Cephalometric comparison between children with and without Down's syndrome. Eur J Orthod. 1988;10:255-263

12 - Suri S, Tompson B, Cornfoot L. Cranial base, maxillary and mandibular morphology in Down syndrome. Angle Orthod. 2010;80:861-869
13- Mohammed A. Korayem; Eman A. AlKofide, Characteristics of Down syndrome subjects in a Saudi sample. Angle Orthod.84:30-37; 2014.

14- Quintanilla J, Biedma B, Rodriguez M, Mora MT, Cunqueiro MM, Pazos MA. Cephalometries in children with Down's syndrome. Pediatr Radiol. 2002;32:635-643

15- A. C. B. Oliveira, S. M. Paiva, M. R. Campos, and D. Czeresnia, "Factors associated with malocclusions in children and adolescents with Down Syndrome," American Journal of Orthodontics and Dentofacial Orthopedics, vol. 133, no. 4, pp. 489.e1-489.e8, 2008.

16- Danielle Bauer, Carla A. Evans, Ellen A. BeGole, and Larry Salzmann. Severity of Occlusal Disharmonies in Down Syndrome. International Journal of Dentistry Volume 2012 (2012), 1 - 6

17 - Brown R, Cunningham W. Some dental manifestations of mongolism. Oral Surg Oral Med Oral Pathol 1961; 14(6):664-676.

18 - Cohen MM, Winer RA. Dental and facial characteristics in Down's syndrome. (Mongolism). J Dent Res 1965; 44:SUPPL:197-208.

19 - Gullikson J. Oral findings in children with Down's syndrome. ASDC J Dent Child 1973;40(4):293-7.

20 - Cohen MM, Arvystas MG, Baum BJ. Occlusal disharmonies in trisomy G (Downs' syndrome, mongolism). Am J Orthod 1970a;58(4):367-72.

21 - Oredugba FA. Oral health condition and treatment needs of a group of Nigerian individuals with Down syndrome. Downs Syndr Res Pract 2007;12(1):72-6.

22 - Spitzer R, Quilliam RL. Observations on Congenital Anomalies in Teeth and Skull in Two Groups of Mental Defectives (A Comparative Study). Br J Radiol 1958 31:596-604.

23 - Spitzer R, Rabinowitch JY, Wybar KC. A Study of the Abnormalities of the Skull, Teeth and Lenses in Mongolism. Can Med Assoc J 1961;18(84(11)):567-572.

24 - Spitzer R. Observations on congenital dentofacial disorders in Mongolism and microcephaly. Oral Surg Oral Med Oral Pathol 1967;24(3):325-32.

25 - Jensen GM, Cleall JF, Yip AS. Dentoalveolar morphology and developmental changes in Down's syndrome (trisomy 21). Am J Orthod 1973;64(6):607-18. 
26 - Asokan S, Muthu MS, Sivakumar N. Oral findings of Down syndrome children in Chennai city, India. Indian J Dent Res 2008;19(3):230-5.

27 - Cohen MM,Arvystas MG, Baum BJ. Occlusal disharmonies in trisomy G (Downs' syndrome, mongolism). Am J Orthod 1970a;58(4):367-72.

28 - Jensen GM, Cleall JF, Yip AS. Dentoalveolar morphology and developmental changes in Down's syndrome (trisomy 21). Am J Orthod 1973;64(6):607-18

29 - Vigild M. Prevalence of malocclusion in mentally retarded young adults. Community Dent Oral Epidemiol 1985;13(3):183-4.

30 - Mitchell L. An Introduction to Orthodontics. 2nd Edition ed: Oxford University Press, 2001. 